\title{
Att skolas till en läsare - om den svenska skolans läsundervisning under 1990- och 2000-talet genom en ung arbetarmans berättelser
}

Stig-Börje Asplund

Institutionen för pedagogiska studier, Karlstads universitet

\begin{abstract}
I artikeln uppmärksammas en ung arbetarmans berättade erfarenheter av den svenska skolans läsundervisning. Utifrån en livsberättelseansats som sätter den berättande människan och dennes erfarenheter i centrum synliggörs hur framväxandet av en läsarhistoria är ett resultat av ett komplext samspel mellan erfarenheter och minnen av skolans läsundervisning och de erfarenheter som gjorts utanför denna kontext över tid. Den läsarhistoria som växer fram samspelar i sin tur med den specifika lokala och historiska kontext i vilken berättelserna ägt rum och med de upplevda förväntningar som vilat på berättaren att vara pojke och man i en svensk skogsbygd. Artikeln synliggör hur läsning görs till en socialt och kulturellt accepterad praktik inom en lokalt förankrad maskulin arbetarklasskultur genom processer där läsningen kopplas till konkreta fysiska handlingar och införlivas $i$ en muntlig berättartradition. Genom dessa transformationsprocesser görs läsningen inte enbart till en "nyttig" eller "vettig" sysselsättning, utan också till en praktik genom vilken en ung arbetarman i skogsbygden utvecklar en identitet som läsare. Studien riktar ljuset mot frågor som kretsar kring vem som är en läsare, och vem som inte är det, vad läsning är och vad det inte är, och på vems eller vilkas villkor. Studien illustrerar också hur de möjligheter att diskutera läsningens vad, hur och varför i skolans läsundervisning riskerar att gå förlorade $i$ en läsdiskurs som betonar läsning av pappersburen typografisk text och som utestänger andra, alternativa sätt att läsa och skapa mening $i$ mötet med olika typer av texter.
\end{abstract}




\section{INLEDNING}

Under senare tid har läsforskningen $i$ allt högre utsträckning uppmärksammat begränsningar i att enbart rikta uppmärksamhet mot könsspecifika aspekter om man vill försöka förstå och förklara pojkars bekymmersamma relation till läsning. Detta exempelvis genom att visa hur sociala kategorier som klass, plats och etnicitet är med och samverkar i pojkars identitetskonstruktion (se exempelvis Brozo, 2019; Hammet \& Sanford, 2008; Scholes et al., 2020). Även skoldiskursen som sådan och dess betydelse för pojkars relation till läsning har studerats närmare av en del läsforskare vars resultat starkt ifrågasätter tidigare argument om läsning som en feminin aktivitet, och att den därför skulle gå i kollisionskurs med pojkars maskulinitetskonstruktion. Moss $(2007,2011)$ understryker exempelvis i sin forskning att pojkars problematiska relation till läsning har att göra med de mycket synliga, binära konstruktioner av elever som antingen "bra" eller "dåliga" läsare som görs i skolans läsundervisning (se också Muntoni \& Retelsdorf, 2018). För att undvika att pekas ut som "svaga" läsare inför sina kamrater, tenderar de pojkar som positioneras som "svaga" läsare, till skillnad från de flickor som gör det, att undvika att engagera sig i läsning av framför allt längre skönlitterära texter. Detta kan på sikt resultera i att dessa pojkar tappar än mer som läsare jämfört med sina klasskamrater (och i relation till flickor). Enligt Moss har pojkars problematiska relation till läsning att göra med kamratförhållanden och den sociala praktiken för skolans läsundervisning i sig. Hon belyser därmed samspelet mellan den sociala kontexten och den sociala konstruktionen av kön och läspraktiker i skolan (se även Cremin et al., 2012; Smith \& Wilhelm, 2002; Young, 2000; Young \& Brozo, 2001).

De ovan nämnda studierna riktar sitt fokus mot elevers hållningar till läsning och läsundervisning här och nu genom intervjuer och/eller observationer av pågående läsundervisning i klassrum. Studier som riktar sitt intresse mot f.d. elevers erfarenheter av skolans läsundervisning saknas i stor utsträckning inom läsforskningsfältet. Inte minst gäller detta studier som fokuserar arbetarpojkar och arbetarmän på landsbygden i svensk kontext (se dock Asplund \& Ljung Egeland, 2020; Asplund \& Pérez Prieto, 2018, för några undantag). Mot denna bakgrund finns ett behov av att studera arbetarmäns relation till läsning över tid utifrån svenska förhållanden och en ansats som lyfter fram läsning i ett större samhällsperspektiv där lokala läspraktikers relation till identitetskonstruktion och tillhörighet uppmärksammas. Syftet med den här artikeln är därför att utifrån en livsberättelseansats fokusera och lyfta fram en ung arbetarman i den svenska skogsbygden, och hans berättade erfarenheter av skolans läsundervisning under 1990-talet och 2000-talet, och spegla dessa mot de sociala och historiska sammanhang i vilka det som berättas äger rum. 


\section{Maskulina läsaridentiteter}

Den dominerande bilden av pojkar, män och läsning har sedan lång tid tillbaka varit just den att de läser mindre och sämre än flickor och kvinnor (Brozo, 2019). En rad studier som gjorts under det första tjugohundratalet vittnar också om ett alltjämt sjunkande läsintresse hos den manliga generationen (se exempelvis Guthrie \& McRae, 2011; SOU 2018:57). Detta är också tydliga mönster som gör sig gällande i såväl nationella som internationella sammanhang. I framskrivandet av pojkars och mäns problematiska relation till läsning kan flera spår identifieras i forskningen. Ett av dessa spår vilket länge varit tongivande i fältet, och vilket omnämns ovan, är hur läsningen som aktivitet kommit på kollisionskurs med pojkars och mäns identitetsskapande arbete. Martino $(1999,2001)$ har exempelvis i sin forskning visat att pojkar som intresserar sig för läsning riskerar att uteslutas ur den manliga gemenskapen eftersom de bejakar något som av deras manliga klasskamrater betraktas som en feminin och suspekt syssla (se också Dutro, 2003; Gilbert \& Gilbert, 1998; Molloy, 2007; Scholes, 2020). Trycket på den enskilde pojken blir därför stort menar Martino, varför läsningen och läsundervisningen också avvisas på grund av rädsla för socialt förtryck av de manliga klasskamraterna. Det sociala trycket har inte minst visat sig vara en närvarande och styrande kraft i arbetarpojkars identitetskonstruktion i skolmiljöer. Här har traditionella maskulina arbetarklassnormer och dissonansen med den medelklasskultur arbetarklasselever upplever att de möter i skolan under lång tid inverkat negativt på arbetarpojkars respons på skola och utbildning. Detta har exempelvis yttrat sig $\mathrm{i}$ form av en antiskolkultur med en avståndstagande hållning gentemot lärare och det undervisningsinnehåll som erbjuds (Mac An Ghaill, 1994; Willis, 1977). Denna motståndskultur finns utförligt beskriven i en mängd anglosaxisk forskning, och även om det existerar strukturella skillnader mellan anglosaxisk och svenska förhållanden finns dessa motståndskulturer bland manliga arbetarklassungdomar även beskrivna $\mathrm{i}$ flera svenska studier (se exempelvis Högberg, 2011; Kontio, 2016; Åberg \& Hedlin, 2015), vilket gör att den relation mellan utbildning, klass och maskulinitet som beskrivs $i$ internationell forskning $i$ flera avseenden är jämförbar med svenska förhållanden. Dessa hållningar är också något som motverkat dessa pojkars och unga mäns möjligheter att hitta in i läsningen och bli en del av skolans läsargemenskap (Alloway et al., 2002; Cann, 2018; Jackson, 2010).

Här finns också i det svenskämnesdidaktiska forskningsfältet en lång tradition och kontinuitet av studier som i olika utsträckning behandlar pojkars avståndstagande till den läsundervisning de möter i skolan. En tidig och central sådan är Malmgrens studie (1992) i vilken Malmgren bland annat visar hur pojkar i en yrkesklass på gymnasiet positionerar sig mot skolans läsundervisning. Enligt Malmgren är detta ett uttryck för en situation där yrkespojkarnas kulturella socialisation kolliderar med den kultur de upplever 
svenskämnet och svenskläraren representerar. Även Molloy (2002, 2007), Olin-Scheller (2006), Hultin (2006), Asplund (2010) och Sundström Sjödin (2019) har i sin forskning visat på pojkars svårigheter att integrera sin egen socialisationsprocess med det undervisningsinnehåll de möter i svenskämnet. Molloy menar exempelvis att det går att tala om en genusimpregnerad läsning (2002) där det bland pojkar (och i deras närmaste sociala krets) finns en utbredd uppfattning om att det är omanligt att läsa skönlitteratur, och Molloy hävdar vidare att detta bland annat har att göra med frånvaron av manliga läsande förebilder (2002, 2007).

Även om dessa studier varit viktiga för förståelsen av pojkars och mäns relation till läsning, har det, framför allt inom det internationella läsforskningsfältet, under senare tid efterlysts mer nyanserade beskrivningar av hur denna relation ser ut; beskrivningar som inte enbart söker sig till förklaringsmodeller som baseras på könstillhörighet. Som en följd av detta har det därför inom läsforskningsfältet under senare tid presenterats studier där uppmärksamheten också riktats mot samspelet mellan olika sociala kategorier som kön, plats och etnicitet och konstruerandet av manliga läsaridentiteter (se exempelvis Asplund \& Pérez Prieto, 2018; Hammet \& Sanford, 2008; Kirkland, 2011; Scholes, 2020; Scholes et al., 2020; Watson, 2011). Entwisle et al. (2007) visar exempelvis att det är pojkar som kommer från socioekonomiskt resurssvaga hem som löper störst risk att få problem med läsningen i skolan, och Wilhelm och Smith (2014) har i sin forskning visat hur pojkar avvisar den läsning de möter i skolan just för att den upplevs som "skolaktig", och inte för att den uppfattas som feminint kodad (se också Smith \& Wilhelm, 2002). Betydelsen av elevers socioekonomiska bakgrund vad gäller läsförståelse och läsintresse framhävs också genom såväl internationella studier som PIRLS (2016) och PISA (2018) som nationella rapporter (SOU 2018:57), vilket vittnar om betydelsen av att också beakta andra kategorier än kön i studiet av pojkars relation till läsning.

Det finns dock studier som visar att det finns pojkar med arbetarklassbakgrund som trots sämre socioekonomiska förutsättningar lyckas utveckla en positiv relation till läsning. Detta sker dock i stor utsträckning utanför skolans domäner (Love \& Hamston, 2004; Scholes, 2019, 2020). Här finns också studier som vittnar om hur vuxna arbetarmän, trots negativa erfarenheter av skolans läsundervisning, utvecklar en identitet som läsare efter det att de lämnat skolväsendet, och som visar på den rurala platsens betydelse för arbetarmäns relation till läsning (Asplund \& Ljung Egeland, 2020; Asplund \& Pérez Prieto, 2018; Comber, 2015; Scholes \& Asplund, 2021). Även om det inom det svenskämnes-didaktiska forskningsfältet har genomförts studier som behandlar marginalisering av läsare, är det fortfarande ont om studier som fokuserar just pojkar och män och som gör det i ljuset av frågor om klasstillhörighet och plats utifrån ett longitudinellt perspektiv. Den här studien bidrar med ett sådant perspektiv och avser att visa hur den svenska 
läsundervisningen under 1990-talet och 2000-talet både inkluderat och exkluderat arbetarpojkar i skogsbygden från skolans läsargemenskap.

\section{TEORETISKA OCH METODOLOGISKA UTGÅNGSPUNKTER}

Frågan om vilken betydelse Patrik ${ }^{1}$, den man som intervjuats för den här studien, tillskriver den läsundervisning han mötte som elev genom det svenska skolsystemet kommer att belysas utifrån ett narrativt perspektiv (Andrews et al., 2013; Kohler Reissman, 2008), och med en vidgad syn på såväl text som läsning (Walsh, 2008). Ansatsen kan mer precist beskrivas som en livsberättelseansats genom vilken jag intresserar mig för Patrik och hans berättelser, och som låter detta utgöra grunden för att försöka förstå de erfarenheter av läsning Patrik väljer att berätta om i de intervjusamtal som genomförts för den här studien. Enligt Pérez Prieto (2006) är det också just detta som utgör styrkan $\mathrm{i}$ ansatsen som sådan. Livsberättelseperspektivet ger oss nämligen tillgång till berättelser om sociala och kulturella förhållanden, händelser och fenomen utifrån berättarens specifika perspektiv och positioner, samtidigt som vi får tillgång till människors berättade erfarenheter och "den historia på vilka dessa positioner och perspektiv vilar" (Pérez Prieto, 2006, s. 290). Metoden som sådan har vuxit sig starkare inom den utbildningsvetenskapliga forskningen där allt fler forskare använt sig av lärares och elevers berättade erfarenheter för att nyansera vår förståelse av skola och utbildning (se exempelvis Asghari, 2014; Asplund \& Pérez Prieto, 2018; Karlsson, 2020; Löfgren \& Karlsson, 2016; Ljung Egeland, 2019; Pérez Prieto, 2000; Webb, 2019).

Centralt för livsberättelseansatsen är att berättande inte äger rum i ett socialt vakuum, utan i specifika sociala, kulturella och materiella sammanhang (Goodson, 2013). Patriks berättande kommer därför att betraktas som en socialt situerad och meningsskapande handling genom vilken han gör påståenden om såväl sig själv, som texter, läsning och skolans läsundervisning och genom vilka han konstruerar gränser och positionerar sig i förhållande till andra (Bamberg, 1997, 2000; Mishler, 1999). Genom den narrativa ansatsen framträder således Patriks läsaridentiteter över tid och sociala positioneringar som "arbetarman", "landsbygdsman" och "skogsarbetare". Lika centralt för ansatsen är också att berättelserna refererar till och är inbäddade i specifika sociala, kulturella, historiska och materiella sammanhang. Min uppgift blir här att försöka rekonstruera den kontext i vilken de erfarenheter som berättas om har genomlevts genom att sätta den i relation till andra berättelser om läsning, teorier och läsdiskurser. Goodson benämner detta som att forskaren relaterar den individuella och personliga berättelsen till "the genealogy of context" (2013, s. 5). Arbetet kan närmare beskrivas som en process genom vilken livsberättelsen formas till livshistoria: 'Life story work concentrates, then, on 
personal stories, but life history try to understand stories alongside their historical and cultural backgrounds" förtydligar Goodson (2013, s. 6).

En annan betydelsebärande del i analysarbetet av berättelser är att lyfta fram de många gånger fragmentariska, snäva och motsägelsefulla berättelser, och de olika perspektiv de bidrar med (Pérez Prieto, 2000, 2006). Med en sådan utgångspunkt är jag därför också intresserad av att låta Patriks berättelser om sin relation till läsning även utanför skolans domän stå i fokus i analysarbetet. Avsikten här är att försöka fånga de många nyanser av Patriks relation till läsning som han ger uttryck för i sitt berättande, med syfte att skapa en djupare förståelse för Patriks berättade erfarenheter av skolans läsundervisning.

\section{Ett intersektionellt perspektiv}

Jag kommer att närma mig Patriks berättelse utifrån ett intersektionellt perspektiv (Cho, Crenshaw \& McCall, 2013; Nash, 2008) där samspelet mellan kön, klass och plats ges en framträdande plats i analysarbetet. Som Crenshaw betonar (1991) är sociala kategorier inte fasta och distinkta utan de överlappar och korsar varandra på otaliga sätt, och genom att ta mig an Patriks berättelse utifrån ett intersektionellt perspektiv blir det möjligt att närmare belysa samspelet mellan läsning, klass, plats och maskulinitet.

I min förståelse av plats vänder jag mig till Massey (2005) som skriver fram platsen som något som har konstruerats och samkonstruerats av människor. Platsen framträder utifrån ett sådant perspektiv som en ständigt föränderlig konstruktion. Genom det ständiga förhandlandet människor emellan utvecklar människor också en känsla av rum vilken innefattar en medvetenhet om att leva på en specifik plats med dess specifika sociala och kulturella praxis, och ett utvecklande av känslomässiga band med platsen över tid (Massey, 2005). Denna syn på platsen och rummet som framförhandlade sociala konstruktioner och det ömsesidiga samspelet mellan plats, rum och identitet är också centrala aspekter i livsberättelseansatsen (Goodson, 2013) och i mitt arbete med att analysera Patriks berättelse.

Lika centralt för min ansats är utgångspunkten att det finns flera maskulinitetskonstruktioner som ständigt konstrueras och rekonstrueras i förhållande till andra positioner (Hearn, 2015). Senare tids kritiska studier av män och maskuliniteter har visat på en förändrad maskulinitetskonstruktion där en hegemonisk eller ortodox maskulinitet som kännetecknas av heteronormativitet, fysisk styrka, kvinnofientliga attityder och emotionell återhållsamhet, utmanas av mjukare och mer inkluderande maskuliniteter (se exempelvis Anderson, 2009; McCormack, 2014; Ward et al., 2017). Dessa förändringar kan naturligtvis också ha påverkat hur arbetarmän införlivar en vad som inom den manliga arbetarklasskulturen traditionellt betraktats som en feminin praktik som läsning i sitt identitetsskapande arbete. 
I min användning av begreppet klass tar jag spjärn emot Bourdieus teoribildning (1984, 1992, 2002), och inte minst hans syn på kulturella praktiker som klassbaserade smaker och livsstilar. Enligt Bourdieu kan klasstillhörighet inte begränsas till ekonomiska tillgångar, utan olika former av kapital och individers vanor, värderingar och handlingsmönster (vilket Bourdieu benämner som habitus) utgör också viktiga aspekter för en individs position i det sociala rummet. Just habitus är förmodligen ett av de mest ifrågasatta begreppen hos Bourdieu då det ofta har uppfattats som ett begrepp som inskränker människors handlingsutrymmen i det att det ofta saknas explicita referenser till just aktörskap (agency) i Bourdieus texter (se exempelvis Archer, 2007; Ingram, 2018). I min förståelse av Bourdieu läser jag dock, liksom den nya generationen bourdieuianska forskare (se till exempel Roberts, 2018; Thatcher et al., 2016), in en mer dialektisk hållning i Bourdieus teoribildning där det ömsesidiga samspelet mellan aktör och struktur istället betonas. Perspektivet innebär att man betraktar strukturer som villkorande och begränsande snarare än determinerande, och att habitus därför kan ses som en konstant interaktion mellan struktur och aktörskap. Enligt Ingram (2018) kan aktörskap därför varken reduceras till strukturer eller ses som något separerat från habitus: "It exists within the habitus and is shaped by and gives shape to the internalised structures", skriver Ingram (s. 57). Den läsning av Bourdieu som den nya generationen bourdieuianska forskare presenterat under senare tid (se också Stahl, 2016) öppnar därför upp för tolkningar där individer också ges utrymme och handlingsfrihet att göra sina egna val och agera därefter, men att dessa val och handlingar samtidigt också alltid är strukturellt villkorade. Detta innebär för min studie att jag inte ser de klassbaserade normer och värderingar som kommer till uttryck i de berättelser om läsning som jag tagit del av som statiska och förutbestämda utan som performativa, kontextuella och förkroppsliga handlingar som uttrycks i den sociala interaktionen med andra.

Studien aktualiserar också frågor om läsning, makt och meningsskapande och den tar här sin utgångspunkt i ett critical literacy-perspektiv som betonar att texter och läspraktiker aldrig är neutrala utan alltid representerar ett perspektiv med en ideologisk ståndpunkt (se till exempel Comber, 2015; Janks, 2010; Luke, 2012). Med ett ursprung i Freires kritiska pedagogik (1993) har critical literacy utvecklats till ett forskningsfält som undersöker maktstrukturer inom utbildningsväsendet med syfte att sätta igång transformationsprocesser som kan bidra till ökad social rättvisa och likvärdighet (Janks \& Vasquez, 2011). Perspektivet innebär för min studie att läsning ses som en transformationsakt genom vilken en läsare inte enbart kan få tillgång till flera olika diskurser utan, även utifrån en underordnad position, kan utöva aktörskap och positionera sig mot maktstrukturer och dominerande diskurser. 


\section{Livsberättelseintervjuer}

Studien bygger på två livsberättelseintervjuer som genomförts med Patrik, en man i 25-års ålder, under 2015. Patrik är uppvuxen i Björkdalen, en mindre ort i Mellansverige och han har under hela sitt liv varit bosatt i bygden. Björkdalen ligger i vad som kan betecknas som en skogsbygdskommun där cirka 7000 av bygdens 11000 invånare bor i mer eller mindre befolkade skogsområden. När Patrik läste på gymnasiet följde han dåvarande Fordonsprogrammets utbildning och han kör sedan några år tillbaka skogsmaskin för ett lokalt företag i bygden. Båda intervjuerna genomfördes i Patriks hem och varade $\mathrm{i}$ totalt två timmar. Intervjuerna spelades in på diktafon och har transkriberats ordagrant. Den första intervjun genomfördes med utgångspunkt i en intervjuguide där Patrik först efter att ha uppmuntrats att berätta om sin nuvarande livssituation ombads att berätta sin livshistoria, med ett fokus på sin relation till och erfarenheter av läsning. Innan den andra intervjun genomfördes transkriberades den första intervjun, och baserat på genomläsningar av denna transkription arbetades en ny intervjuguide fram vilken syftade till att uppmuntra Patrik att berätta mer ingående och/eller utveckla områden/ teman från den första intervjun vilka jag uppfattade som fragmentariska och/eller outvecklade. Under den andra intervjun utvecklade Patrik också sin egen berättelse om sitt liv och sin relation till och erfarenheter av läsning på eget initiativ, vilket är vanligt inom ansatsen. Intervjuerna med Patrik har genomförts som en del av ett större forskningsprojekt där män som gått en traditionellt mansdominerad yrkesutbildning intervjuats om sin relation till läsning, och Patrik har valts ut av det skälet att hans berättelser ger en representativ bild av det insamlade materialet. Studien följer Vetenskapsrådets riktlinjer (2017) om god forskningssed och etik i vetenskaplig forskning som innefattar människor, vilket bland annat inneburit att Patrik informerades såväl muntligt som skriftligt om studiens syfte och fick ge sitt skriftliga samtycke till att delta $i$ studien.

I min analys har jag närmat mig Patriks berättelser från en vidgad syn på begreppet text och läsning och i min presentation har jag valt att lyfta fram en så mångfacetterad bild av hans läsarhistoria som möjligt. Jag har därför valt att även inkludera Patriks berättelser om vad han har läst och i vilka sammanhang även utanför en skolkontext, och intresserat mig för de identitetsanspråk som görs i berättandet, hur han positionerar sig som läsare, och hur han placerar sig själv i relation till andra läsare. Inledningsvis har Patriks berättade erfarenheter konstruerats till en sammanhängande berättelse, för att därefter analyseras som berättelser med ett fokus på de identitetsframträdanden och positioneringar som görs (Bamberg, 1997; Kohler Riessman, 2008). Här har sedan analytiska begrepp som läsaridentitet och läsarhistoria använts för att begreppsliggöra Patriks relation till läsning över tid (se Asplund \& Pérez Prieto, 2018). I denna fas har jag också intresserat mig för hur klass, maskulinitet och plats görs i berättandet. 
Genom att uppmärksamma hur identitet konstrueras i livsberättelseintervjuerna närmar jag mig också det performansbaserade perspektivet på berättelser som utvecklats av Bamberg $(1997,2000)$ och Mishler (1999). Såväl Bamberg som Mishler betonar vikten av att betrakta berättelser som socialt situerade, det vill säga att berättelser och berättarens identitetsanspråk samspelar med den omgivande kontexten. Ansatsen innebär också att jag $\mathrm{i}$ min analys av Patriks berättelser intresserar mig för den bredare kontexten som omger Patrik, vilken exempelvis innefattar dominerande diskurser om vad läsning är och inte är (se exempelvis De Fina, 2013; Kohler Riessman, 2008).

\section{RESULTAT}

\section{Negativa erfarenheter av skolan}

I det hem Patrik är uppvuxen saknas akademiska traditioner. Hans föräldrar har främst arbetat inom servicesektorn och för Patrik har det aldrig varit tal om något annat än att han skulle skaffa sig en "mekanisk utbildning" som han säger. Vägen till den utbildningen har dock kantats av en hel del negativa upplevelser av skola och studier. Skolan har aldrig varit något som Patrik har uppskattat, och i den berättelse som utkristalliseras genom Patriks berättande om sin resa genom det svenska skolsystemet framträder en tydligt avståndstagande hållning till såväl skola och lärare som den undervisning han mötte. När Patrik berättar om sig själv som elev berättar han också att han ofta hamnade i dispyter med lärare vilket resulterade i flertalet möten med skolans rektorer:

Rektorn var det ju ganska vanligt att man satt hos för dom fick ringa till mamma å pappa när man hade gjort nått dumt. Jag har nog aldrig varit en bra elev, det kan jag aldrig tro. Man har nog haft lite mycket jävulskap för sig genom åren.

För Patrik var skolan helt enkelt något av vuxenvärlden konstruerat nödvändigt ont som man måste genomlida som elev. Redan under högstadiet kände sig Patrik "less" på skolan och den undervisning han mötte och han berättar att det "enda" han tänkte i skolan "det var ju Gud när får jag sluta med den här skiten å börja å jobba å tjäna pengar?". Den kunskap skolan förmedlade beskriver Patrik som avlägsen och verklighetsfrånvänd:

Allt i skolan blir så mycket utfyllnad, allmänbildning. Vad man än gör så ska det liksom tuggas in gammal skit som alltid har funnits i skolan också då. Det är ju säkert mycket som man är tvungen å lära sig fastän ingen egentligen kan säga vad du har för nytta av det. [...] Sen skulle man lära sig vilka städer som finns nere i Asien, det vet jag ju inte hur jag skulle 
komma ihåg än idag för man har ju inte, man måste få göra sig, som en annan var som elev så måste man få verklighetsförankring [...] Men just det här med att det skulle tuggas in... ja, bara för att, utan att det liksom fanns nån anledning till det.

Enligt Patrik har det också alltid funnits två typer av elever i skolan; de som har engagerat sig i skolarbetet och de som inte har gjort det. Patrik tillhörde den senare kategorin säger han, och någon vidare kontakt med de så kallade "bokmalarna" som läste mycket och som engagerade sig i skolarbetet hade han inte.

\section{Att göra lagom mycket}

Ett genomgående tema är alltså hur Patrik pratar om skolan i negativa termer; den var tråkig, långsam, repetitiv, ointressant och många gånger totalt meningslös. Trots dessa negativa erfarenheter har Patrik gjort det skolan och lärarna har krävt av honom. Han är dock tydlig med att påpeka att han aldrig gjort mer än vad han ansåg sig behöva för att klara sig:

Patrik: Det har ju alltid varit noga att man ska vara i skolan på morron å när man kommer hem från skolan så skea jag göra läxorna. Det har ju varit, sen att jag att man alltid har varit en vildbas å höll på med detta det har ju varit en sak då, å man har fått lite skäll för det då. Men just det med att man skulle göra det man ska, det man blir tillsagd i alla fall då liksom.

Intervjuare: Har du gjort det? När du ser tillbaka nu, på ditt liv i skolan?

Patrik: Jag har aldrig gjort nått mer än jag behövt.

När Patrik gick i åttonde klass fångade dock vuxenvärlden upp honom vilket fick konsekvenser för hans fortsatta skolkarriär. Patriks frånvaro började bli alltför hög vilket gjorde att lärare och elevvårdsteam slog larm, och tillsammans med Patriks föräldrar lyckades de uppmuntra honom att ta tag $\mathrm{i}$ sina studier. Patrik beskriver denna episod som en vändpunkt då han förstod att om han skulle fortsätta den inslagna banan skulle det bli svårt för honom att kunna studera vidare på gymnasiet för att sedan få ett jobb.

Patrik: Att man var tvungen för sin egen skull i slutändan. Det var säkert det som gjorde att det vände då.

Intervjuare: Var målet att få ett jobb då framöver eller? 
Patrik: Ja, det var väl det som alltid har varit det hotet var ju att du kommer inte du måste ju ha ett jobb, du måste ju ha ett betyg så du får en utbildning som du sen får ett jobb av.

Intervjuare: Var har hotet kommit ifrån?

Patrik: Nej, men det är ju allt ifrån hemifrån till skolan. Det är ju kuratorn å alla dom här mamma å pappa har ju alltid liksom talat om att du måste ju ha en utbildning å du måste ju göra det här för å få dom betygen som tar dig dit å dit å det. Det är väl det kanske som en annan tycker är konstigt resonemang där med betygen egentligen eftersom jag skulle in på fordon så vet jag inte varför jag skulle vara duktig i det ena å det andra ämnet om man inte ska bli professor eller nått sånt där. Jag vet ju inte vad jag gör med mitt MVG i engelska det har jag ju ingen nytta av så hade jag mina G:n så kom jag ju dit jag ville ändå.

Genom Patriks berättande framträder så bilden av en elev som inte alls finner sig med den undervisning han möter i skolan. Så här i efterhand kan han fortfarande inte förstå vitsen med vissa ämnen, och framför allt inte dess innehåll vilket Patrik mer upplevde var något som upprepades genom utantillövningar där det fanns få kopplingar till den värld Patrik rörde sig i. Men, trots detta rättar han in sig i ledet, efter framför allt påtryckningar från skola genom elevvårdsteam och kuratorer, men också med stöd av sina föräldrar.

\section{Mötet med en läsundervisning}

Ett av de ämnen i skolan som Patrik tillskriver viss nytta, men som han ändå beskriver i mycket negativa ordalag är svenskämnet. Svenskämnet som sådant beskriver Patrik som ett ämne där undervisningen genom de olika stadierna $\mathrm{i}$ skolan "har gått runt i cirklar" och i hans beskrivning framträder ämnet som ett färdighetsämne där fokus låg på förmågorna att stava, skriva och läsa. Själva läsningen i skolan, som Patrik minns den, gick mestadels ut på att läsa "kortare texter" på "A4 papper" som skulle sammanfattas och sedan redovisas skriftligt för läraren, oftast i form av så kallade recensioner. Överlag har Patrik få konkreta minnen av skolans läsundervisning, annat än att själva läspraktiken som sådan var en tråkig tillställning där det mer handlade om att visa upp att man hade läst något, än vad man läst och vad läsningen gjorde med honom. Patrik upplevde också $i$ ett tidigt skede att skolan och hans lärare missförstod honom, och hans uppvisade motstånd mot studierna bottnade inte i några svårigheter att lära och förstå, utan snarare var motståndet ett resultat av skolans misslyckande med att göra undervisningen meningsfull och relevant för Patrik.

Överlag beskriver Patrik den läsning han mötte i skolan som ointressant och meningslös. De texter som skolan tillhandahöll saknade både mening och sammanhang då han upplevde att de inte knöt an till hans egna erfarenheter 
och intressen. För att härda ut och för att klara sig igenom med ett godkänt betyg i svenskämnet utvecklade han olika strategier. En strategi var att göra så lite som möjligt, men ändå tillräckligt för att klara studierna. Konkret kunde detta innebära att Patrik läste valda delar ur ett verk för att om möjligt kunna skaffa sig överblick över vad den aktuella texten handlade om, och för att ge sken av att han läst det som förväntades av honom. Strategin är dock mer genomtänkt än vad den vid en första anblick kan verka vara och har också konkreta kopplingar till Patriks liv utanför skolan. Desto mindre arbete han tog med sig hem från skolan, desto mer tid skulle han kunna ägna åt andra aktiviteter och intressen än just skolarbete. En annan variant av strategin "att göra så lite som möjligt men ändå tillräckligt" blev då också att aktivt och medvetet välja ut böcker som han föreställde sig skulle bli så enkla som möjligt att ta sig igenom, men som fortfarande hamnade inom ramen för vad lärarna skulle acceptera som tillräckligt:

En annan som inte hade intresset kolla ju nästan efter det som hade större text och mindre sidor än det som man kanske skulle ha valt egentligen då. Jag vet inte det är väl, i skolan, man hade ju, man var ju där i dessa åtta timmarna om dagen eller vad det var, sju, då hade man inget intresse av å göra detta. När man kom hem då ville man ju göra allt det andra [....] Det var väl till å utöka fritiden om man säger som man ville göra allt det andra. Så då tog man ju det som gick fortast å lättast så man skulle göra så lite som möjligt så man hann å göra allt det andra.

I exemplet ovan tydliggör Patrik att han upplevde de många timmar han ägnade åt skolarbete under lektionstid var tillräckligt mycket tid och at han då inte fann någon anledning att låta skolan inkräkta för mycket på hans fritid. Att välja kortare texter med "större text" blev då en strategi att ta till för att undvika att få med sig för mycket skolarbete till hemmet och istället "utöka" den värdefulla fritiden.

\section{Ljudböcker}

För att "slippa" läsa texter och för att klara sig igenom vissa längre böcker som skulle läsas i skolan lyssnade Patrik också på ljudböcker. Just ljudbokslyssnandet beskriver Patrik inledningsvis som "fusk"; en ståndpunkt han kort därefter nyanserar något:

Patrik: Ja, det var mycket fusk där då.

Intervjuare: Jaha. (skratt)

Patrik: Det var liksom-

Intervjuare: Hur gör man det? 
Patrik: Ja, men kunde ta nån ljudbok från pappa å höra på så då.

Intervjuare: Men är det fusk det tycker du?

Patrik: Ja det tror jag det. Njae de, det kan man väl diskutera om det är eller inte, det är väl bara det att jag slapp å plåga mig själv å läsa istället då men sen att man gjorde ju. Resultatet blev ju det, du skulle ju förstå å du ska ju liksom sammanfatta å göra den här redovisningen i slutändan, så den delen blir ju densamma.

Eftersom själva poängen med läsningen i skolan, sådan Patrik uppfattade den, framför allt handlade om att läsa pappersburna texter och producera fram en sammanfattning genom vilken man för läraren visade att man läst och förstått det lästa, kunde han lika gärna bespara sig från att "plåga" sig själv med läsningen som sådan och lyssna på ljudböcker istället. Eftersom slutprodukten ändå blev densamma var själva tillvägagångssättet därför av mindre betydelse. Något senare $\mathrm{i}$ sin berättelse återkommer Patrik till redovisningarna av de texter och böcker man skulle läsa i skolan och i exemplet nedan kritiserar han skolans läsundervisning:

Patrik: Man var tvungen att göra allt på ett visst sätt. Du får inte ha egna lösningar på det för skulle man lämna in en redovisning på en bok å man har gjort den i slutändan så är ju frågan hur man har gjort den, för så att man har tagit det i färdigt ifrån Internet det har man ju aldrig gjort så men, det är ju frågan hur man har fuskat sig till det.

Intervjuare: Men när du pratar om att du lyssnat på ljudböcker inom skolan då menar du att det var nästan så att du kände att du fuskade?

Patrik: Ja ja, det var ju det att man visste ju att man var ju tvungen att ha denna jävla boken framför sig å dra dom här sidorna fram å tillbaka det var ju-

Intervjuare: Men var kommer det ifrån tror du, just den känslan då, är det nått du fått från skolan då att det är fel å läsa via ljudböcker?

Patrik: Nej, det var väl. Nej, man har väl säkert en bild om att så här ska man göra det. Å då vet man att gör jag inte så, så är det fel hur jag än bär mig.

Ännu en gång återkommer så Patrik till den slutprodukt som skulle produceras efter en genomförd läsning, det vill säga den skriftliga redovisningen eller recensionen av boken, och det framkommer också tydligt att han i samband med detta tillskriver skolan en förmedlarroll av en lässyn där man förväntas sitta med "denna jävla boken" framför sig och "dra dom här sidorna fram å tillbaka". Läser man inte på det sättet läser man fel. 


\section{Läsning innan, utanför och efter skolan}

För att förstå Patriks hållning och relation till den läsning han möter i skolan är det också nödvändigt att sätta den i relation till vad Patrik berättar om den läsning han ägnat (och ägnar) sig åt utanför skolans domäner. För, trots de negativa erfarenheter av skolans läsundervisning som Patrik uppehåller sig mycket kring när han pratar om läsning, och trots att han tidigt under den första intervjun positionerar sig som en icke-läsare som dessutom upplever sig ha svårt för att ta sig igenom längre typografiska texter, betonar han vikten av att kunna läsa:

Ja, men det kommer man ju inte ifrån läsa måste man ju kunna. Man måste ju kunna tyda allt emellan vägskyltar för å ta sig nånstans till att göra rätt för sig i livet på nått vis. Det är klart läsa, det är obligatoriskt. Jag menar man kommer inte värst långt här i världen om man inte kan läsa, det gjorde man ju inte.

Läsningen som sådan är en aktivitet som man inte kan komma ifrån menar Patrik, och desto längre in i hans berättelse om sin relation till läsning vi kommer, desto mer mångfasetterad blir också hans hållning, vilket också gör det möjligt att skriva fram en mer nyanserad berättelse om hans relation till läsning. Patrik tillskriver också, trots sin kritik mot skolans läsundervisning, skolan en viss betydelse över att han idag kan läsa "snabbt". Inte minst lyfter Patrik här fram de repetitiva inslagen i skolans läsundervisning som betydelsefulla för hans möjligheter att idag kunna ta sig igenom texter snabbt.

\section{Från läsning till manuellt arbete}

Det finns också två spår som framträder i Patriks berättelser om läsning som båda är kopplade till ett manuellt arbete. Det ena spåret rör Patriks läsning av de texter som han möter $\mathrm{i}$ jobbet och texter han tar sig an genom sina fritidsintressen vilka framför allt kretsar kring motorfordon och jakt. En tidig sådan läsupplevelse som Patrik berättar om vilken på många sätt varit betydelsefull för hans relation till läsning är då han som tioåring får fatt i en instruktionsbok till en ny bil som hans pappa precis hade köpt:

Jag vet när farsan köpte den första, första nya Volvon han köpte. Den instruktionsboken läste jag nog så jag kunde varenda data på de där Volvorna utantill, för då hade man ju, ja det var ju så jävla roligt å å kolla vad det fanns för utbud å å läsa för då var man ju intresserad. Så då, det vet jag, var det var en jävla instruktionsbok som jag satt å läste igenom hundratals gånger tänker jag. A det var, det var allt ifrån var säkringarna satt å vad det fanns för system i bilen om man säger. 
Just den här läsningen av instruktionsböcker är en läsning som kommer att följa Patrik genom åren och genom faderns bilinköp, och drygt tio år senare kommer Patrik att återkomma till den här typen av läsning när han som anställd på en bilverkstad kan nära sitt intresse för hur bilar fungerar genom att bland annat läsa manualer och instruktionsböcker:

\begin{abstract}
När jag jobba på Volvo då lusläste man ju om liksom inne i datasystemen lite om dom också då för å se...ja hur det var uppbyggt så det är väl såna grejer som fångar en annans intresse av att läsa. Då hade man ju...som man, ja för min del hade jag ju ett syfte för då skulle jag ju kunna å veta vad det var för något. Men det var väl det som aldrig kom i skolan, att jag såg ingen anledning till nånting som vi gjorde där.
\end{abstract}

Patriks vilja att förstå hur bilar, bilmotorer och andra motorburna fordon fungerar och hur de kan repareras när de är trasiga är en starkt drivande motivationsfaktor i Patriks läsning. Ofta handlar det om att han har sett hur någon annan "byggt sig en motor eller nått" och genom att läsa om detta kan han få information om hur andra har gjort och på så sätt lära sig en del nytt. I stor utsträckning läser Patrik då digitala texter på sin mobiltelefon, och när han pratar om den här typen av texter och läsning gör han det också ofta $i$ termer av att vad han då i själva verket ägnar sig åt är ett sorts "problemlösningsarbete". Givet att han då har ett tydligt mål med läsningen resulterar detta i en lässtrategi vilken han benämner som "punktläsning":

Patrik: Ser jag nått intressant så som jag liksom fastnar för nått nytt vapen eller nån artikel liksom så läser man den så men punktläser mer, vad jag gör $i$ alla fall. Liksom jag skulle aldrig kunna sitta å ta sida för sida å ta mig fram å, det skulle ju ta hur länge som helst för mig å läsa då. Det är ju detsamma när man letar också, då har man ju denna punktläsningen när man läser problemlösningar då, då är det ju scrolla å läser å går tillbaka eller framåt då så det.

Intervjuare: Vad menar du med punktläsning? Vad är det för nånting?

Patrik: Nej men alltså till att bara jag grovläser ju jag kanske tar en mening å så bara rullar man en bit tar dom här letar sig fram efter dit man ska då så man... skulle ju aldrig sitta å plöja allt för att det är intressant mer än att vill jag ha reda på...på ett svar så letar jag ju mig fram till det, även om det tar en säkert två gånger innan dit så. Just det här med att sitta å plöja blir aldrig av utan man sitter å strö- ströläser på bara.

En betydande del av den läsning Patrik ägnar sig åt idag har alltså direkta kopplingar till ett manuellt fysiskt arbete; han läser för att lösa olika problem som är knutna till hans arbete som skogsmaskinförare, eller till hans fritidsintressen som rör jakt och motorer. På så sätt läser han texter vars innehåll 
han sedan kan omsätta i en konkret fysisk kroppslig och/eller maskinell handling.

\section{Bland ljudböcker och skogsmaskiner}

Det ljudbokslyssnande Patrik ägnade sig åt som elev då han "fuskade" sig igenom några böcker på högstadiet är en aktivitet han fångat upp i vuxen ålder. I arbetet som skogsmaskinsförare blir arbetsdagarna under högsäsong mycket långa. Arbetspass på upp till 16 timmar om dagen under dessa perioder är inte ovanligt och under senare år har Patrik börjat lyssna på ljudböcker under passen:

Dagarna som en annan gör på sommaren, det är ju pass emellan tolv å sexton timmar å det kan ju va en hel ljudbok. Då får du den i ett svep å det skulle ju jag skulle då aldrig orka å läsa en bok i ett svep det vet jag ju, så det är väl just det som gör att man orkar å bilda sig, för annars ska jag läsa nånting å så går det tre fyra dagar å så ska jag läsa igen då har jag ju nästan glömt bort vad jag läst. Men det blir ju att man hör på ljudboken eller att man...då går det ju i ett konstant [...] ja, det rullar ju hela tiden dessa liksom i bakgrunden om man säger då. Det är väl det som är lättare med det för min del då än att sitta å läsa.

Patrik berättar att han under vissa perioder kan "klämma" upp till tre, fyra böcker per arbetsvecka och inte sällan har han då tagit sig igenom flera böcker som ingår i samma serie. Några av de författare vars böcker Patrik lyssnat på är bland annat Henning Mankell, Jan Guillou, Fredrik Backman och Camilla Läckberg.

Ett genomgående tema i Patriks val av texter som han lyssnar på (detta gäller också hans val vad gäller film och TV-serier) är att det ska hända mycket; "Ju mer det händer ju roligare blir det" säger Patrik. Blir det för mycket miljöbeskrivningar eller utförliga karaktärsbeskrivningar riskerar man att "komma från handlingen" och då tappar han intresset:

För det är väl, är det Guillou det eller vem fan är det som kan berätta om en Colt i fyra timmar i princip, liksom då händer det ju ingenting utan karaktärerna måste ju göra nånting i det också då. Sen om det inte är nått vettigt egentligen då om man tänker efter då men det är ju just att det ska ju, det måste ju rulla framöver det kan ju inte va $\mathrm{i}$ en scen $\mathrm{i}$ ett helt kapitel eller om man tittar på eller läser en bok så det måste ju röra sig framöver hela tiden så att man inte blir uttråkad i det som är så man kommer ifrån handlingen.

Patrik är heller inte ensam om att lyssna på ljudböcker bland männen i det företag han arbetar för. Han har flera kollegor som också lyssnar på ljud- 
böcker och de brukar prata med varandra om det de lyssnat till och ge varandra tips på böcker som de rekommenderar andra att lyssna på.

\section{Att förena nytta med nöje}

För Patrik är dock boklyssnandet en aktivitet som ska göras samtidigt som han gör något annat; något "nyttigt". Att "bara" lyssna på ljudböcker betraktar han som slöseri med tid. Denna form av boklyssnande jämställs därmed med den mer solitära formen av läsning av skönlitterära romaner, en läsaktivitet som Patrik inte riktigt känner sig bekväm med.

Patrik: Det är klart i ett tidigt stadium så kanske det var viktigt, men sen när det är klart om nån skulle sitta å högläsa för mig nu skulle jag bli så uttråkad så jag satt å gjorde nått annat. Att det...

Intervjuare: Det är skillnad på det och att det är ljudböcker?

Patrik: Nae men då gör jag ju nånting under tiden. Då sitter jag å kör å då gör jag ju jobbet men skulle jag stanna å göra å sitta å läsa då skulle jag känna mig så oeffektiv så då skulle jag inte orka med det då liksom, men om jag hade rast så. Det är väl det här nervösa som en annan har i sig att man ska liksom göra nånting. Endera gör jag absolut ingenting å då gör jag ingenting, men sen när jag gör nånting så måste jag ju göra nånting. Så det är väl det som är. Jag ser det som ett, det blir ett moment om man ska sitta å läsa hela tiden extra för att man ska se hur dom är. Det är för, är för omständligt på nåt vis.

I exemplet ovan återkommer Patrik till vad han beskriver som sitt "rastlösa" beteende och att han inte har den ro som krävs för att sitta och lyssna på en ljudbok, eller "bara" ägna sig åt att läsa en bok. Han måste helt enkelt göra någonting samtidigt för att inte känna att tiden bara rinner iväg och att han inte gör någon "nytta".

\section{DISKUSSION}

I artikeln har intresset riktats mot en ung arbetarmans berättade erfarenheter av läsning utifrån en livsberättelseansats som sätter den berättande människan och dennes erfarenheter $\mathrm{i}$ centrum. Utgångspunkten för användandet av ansatsen har varit att människors erfarenheter och berättelser kan bidra med viktig kunskap om pedagogiska fenomen. Det longitudinella perspektiv som ansatsen bidrar med möjliggör också kunskap om det liv som har levts i det förflutna, och vad dessa levda erfarenheter inneburit för människan på sikt (Goodson, 2013; Pérez Prieto, 2006). Här har analysen av Patriks berättade erfarenheter synliggiort hur framväxandet av en läsarhistoria är ett resultat av ett komplext samspel mellan erfarenheter och minnen av skolans läsunder- 
visning och de erfarenheter som gjorts utanför denna kontext över tid. Artikeln bidrar således med ökad förståelse för den roll och betydelse skolans läsundervisning har givits i en ung arbetarmans liv och hur dessa erfarenheter har samspelat med konstruerandet av en (maskulin och rural) läsaridentitet (se också Scholes \& Asplund, 2021).

När Patrik ser tillbaka på sin tid som elev med nuet som utgångspunkt (Freeman, 2010) domineras hans berättelse av negativa erfarenheter av såväl skolan som institution som den läsundervisning han mött. Patriks erfarenheter som elev kan här kopplas till det Oser (2012) beskriver som negativ kunskap. Negativ kunskap avser minnen relaterade till händelser, saker och procedurer som upplevs som falska eller otillräckliga. Dessa minnen är också kopplade till känslor som skam, skuld eller bestraffning som dessa negativa upplevelser härrör från. Negativ kunskap är också en central del av arbetarklassungdomars lärande eftersom så många av de erfarenheter de har från skolan är negativa upplevelser (Goodson, 1996; Willis, 1977) och i flera avseenden går det här att dra paralleller till de många brittiska arbetarklassungdomar Reay (2017) följt i sin forskning. Ett återkommande inslag i Reays material är de berättelser som vittnar om språkliga och kulturella krockar, där elever med arbetarklassbakgrund ofta upplever ett främlingskap med den undervisning de möter i skolan (se också Ingram, 2018; Roberts, 2018; Skeggs, 2004), vilket också riskerar att skapa "skadade" lärandeidentiteter (Reay, 2017, s. 63). För Patriks del innefattar detta också erfarenheter av en läsundervisning som inte berörde honom och vars innehåll var honom främmande. Det innefattar också en känsla av att befinna sig utanför skolans läsargemenskap, och det är också i ljuset av detta som Patriks avståndstagande hållning till läsundervisningen ska förstås. De strategier Patrik utvecklar för att "härda ut" läsundervisningen bottnar således inte i en hotad maskulinitetsbild där läsning förknippas med femininitet utan för att han upplever den som just "skolaktig" och att lärarna inte bryr sig om att förankra vare sig läsningen, dess syfte eller de texter som ska läsas hos honom själv.

Genom Patriks berättelser framträder på så vis erfarenheter av möten med en läsundervisning vilken vilar på en autonom (Street \& Street, 1984) syn på literacy utifrån vilken literacy betraktas som en kognitiv förmåga som kan läras in (och ut) oberoende av kontext. Den läsundervisning Patrik talar om handlar således mer om färdighetsträning där övervakning av läsprestation snarare än inre motivation utgör den drivande kraften. Analysen av Patriks berättelser visar således hur skolans läspraktik (läsundervisningen som sådan och det texturval som görs) representerar specifika perspektiv med ideologiska ståndpunkter (Comber, 2015; Luke, 2012) och att detta får konsekvenser för Patriks relation till läsning och bild av sig själv som läsare.

Vad Patriks berättelser också visar är att läsningen blir meningsfull för honom först när den kopplas till hans egna intressen och när det finns ett tydligt uttalat syfte med den. Detta är också faktorer som tidigare forskning 
visat är betydelsefulla för en framgångsrik läsundervisning (se exempelvis Roe, 2014; Wilhelm \& Smith, 2014). För Patriks del är detta dock något som sker först utanför skolans ramar och således på Patriks egna initiativ. Patrik läser redan i tidig ålder avancerade tekniska instruktionsböcker och manualer och han läser ofta och mycket digital text för att lära sig hur något fungerar. Här framträder en tydlig drivkraft i Patriks läsning att vilja förstå hur saker och ting hänger samman, och det är också genom denna "problemlösningsläsning” Patrik skapar mening i läsningen.

Men förutom valet av texter är det också möjligt att här tala om en process genom vilken Patrik omsätter sin läsning i konkreta fysiska handlingar vilka har direkta kopplingar till skogsbygd och Patriks intressen i form av exempelvis jakt och att meka med olika motorfordon. Denna transformationsprocess sker även genom Patriks ljudbokslyssnande genom vilken han kan ta del av skönlitterära texter samtidigt som han kan ägna sig åt manuellt arbete när han kör skogsmaskin (jfr Tattersall Wallin \& Nolin, 2020). Tillsammans med sina arbetskamrater skapar han sedan utrymmen att föra samtal om de texter han mött genom ljudböckerna. Som Massey (2005) påpekar förhandlas platser och identiteter kontinuerligt vilket möjliggör skapandet av något nytt. När Patrik reflekterar över sin relation till läsning över tid, och utifrån en utsiktsplats i nuet, gör han det delvis i relation till de upplevda förväntningar som vilat, och vilar på honom som pojke och man i ett specifikt lokalt och historiskt sammanhang (Connell, 1995; Mac an Ghaill, 1994). Men samtidigt görs läsningen, genom de transformationsprocesser som synliggörs genom Patriks berättande, också till en legitim och socialt och kulturellt accepterad praktik inom den specifika maskulina och rurala arbetarklasskultur som Patrik är en del av, och vilken han själv är med och rekonstruerar (jfr Asplund \& Goodson, 2020). Med Janks (2010) terminologi kan dessa transformationsprocesser beskrivas som processer genom vilka Patrik, utifrån en underordnad position utövar aktörskap och re-designar och konstruerar nya versioner av den dominerande läspraktik som omgett (och omger) honom. Dessa re-designade läspraktiker framstår också som praktiker där läsningen inte enbart görs till en legitim och "nyttig" eller "vettig" sysselsättning utan en aktivitet genom vilken Patrik tillsammans med andra konstruerar en läsargemenskap och utvecklar en identitet som läsare.

Genom att ta del av en ung arbetarmans berättade erfarenheter av läsning utifrån ett narrativt perspektiv som sätter den berättande människan och dennes erfarenheter i centrum (Pérez Prieto, 2000, 2006) blir det möjligt att visa hur framväxandet av en läsarhistoria är ett resultat av ett komplext samspel mellan erfarenheter och minnen av skolans läsundervisning och de erfarenheter som gjorts utanför denna kontext över tid (Asplund \& Pérez Prieto, 2018). Dessa erfarenheter samspelar i sin tur också med den specifika lokala och historiska kontext i vilken Patriks berättelser ägt rum (Massey, 2005) och där Patriks läsarhistoria kan ses som ett uttryck för maskulina 
arbetarklassbaserade smaker och livsstilar (Bourdieu, 1992) som förkroppsligas av honom $i$ hans berättande om hans relation till läsning genom livet (se också Asplund \& Ljung Egeland, 2020).

Utifrån ett critical literacy-perspektiv riktar Patriks berättelser om sina erfarenheter av läsning ljuset mot frågor som kretsar kring vem som är en läsare, och vem som inte är det, vad som är läsning och vad som inte är det, och på vems eller vilkas villkor (se Janks, 2010). Här synliggör Patrik också, genom sina berättelser, hur de texter och den läsning han möter i skolan representerar intressen och perspektiv genom vilka Patrik utifrån sin underordnade position positioneras som en ointresserad och svag läsare (jämför Comber, 2015; Moss, 2007, 2011; Sundström Sjödin, 2020). I ett avseende visar analysen dock att det nödvändigtvis inte behöver vara Patrik själv, det vill säga den unge arbetarmannen i skogsbygden, eller läsningen som sådan som utgör "problemet". Snarare skulle man kunna hävda att det är den skola som Patrik berättar om som, utifrån sin specifika position och syn på läsning, har misslyckats med att inte enbart identifiera och införliva den livsvärld Patrik bär med sig in i klassrummet som elev i läsundervisningen, utan också med sin begränsade syn på vad, hur och varför man läser, förminskat Patrik som läsare (se också Asplund \& Olin-Scheller, 2021; Persson, 2015; Scholes, 2019, 2020; Scholes \& Asplund, 2021; Sundström Sjödin, 2020). Sett utifrån det perspektivet framträder också den svenska skolan som den begränsade plats som bland annat Roberts (2018) menar att skolan utgör för många pojkar och unga män med arbetarklassbakgrund, i det att den begränsar möjligheterna för Patrik att betrakta sig som läsare i en skolkontext. Men inte minst visar Patriks berättelser på de möjligheter att diskutera läsningens vad, hur och varför i skolans läsundervisning (se exempelvis Persson, 2012, 2015; Sanford \& Blair, 2008; Schmidt, 2018) som riskerar att gå förlorade i en läsdiskurs liknande den Patrik mött, och som betonar läsning av pappersburen typografisk text och vilket utestänger andra, alternativa sätt att läsa och skapa mening i mötet med olika typer av texter.

\section{NOTER}

${ }^{1}$ Alla personnamn och namn på platser är fingerade. 


\section{REFERENSER}

Alloway, Nola, Freebody, Peter, Gilbert, Pam, \& Muspratt, Sandy (2002). Boys, literacy and schooling: Expanding the repertoires of practice (Commonwealth Department of Education, Science and Training report). Griffith University. http://www.gu.edu.au/school/cls/clearinghouse/

Anderson, Eric (2009). Inclusive masculinity: The changing nature of masculinities. Routledge.

Andrews, Molly, Squire, Corinne, \& Tamboukou, Maria (red.) (2013). Doing Narrative Research. Sage Publications.

Archer, Margaret S. (2007). Making your way through the world. Cambridge University Press.

Asghari, Hamid (2014). Från uppväxt till lärargärning: En livsberättelsestudie med åtta yrkeslärare på industritekniska programmet. [Doktorsavhandling, Karlstads universitet].

Asplund, Stig-Börje (2010). Läsning som identitetsskapande handling. Gemenskapande och utbrytningsförsök i fordonspojkars litteratursamtal. [Doktorsavhandling, Karlstads universitet].

Asplund, Stig-Börje, \& Goodson, Ivor (2020). Between oral and written culture: An exploration of a Swedish working-class man's learning trajectory. 13:e konferensen om berättelseforskning, Karlstad University, 19-20 November, 2020.

Asplund, Stig-Börje, \& Ljung Egeland, Birgitta (2020). Maskulina läspraktiker genom tid och rum. Educare - vetenskapliga skrifter, (4), 33-59.

Asplund, Stig-Börje, \& Olin-Scheller, Christina (2021). Reading practices in transformation. Re-designing print-based literacy mindsets in the Swedish digital classroom. L1 Educational Studies in Language and Literature, 21 (Special Issue Working with Literature in Nordic Secondary Education), 1-27.

Asplund, Stig-Börje, \& Pérez Prieto, Héctor (2018). Young working-class men do not read: or do they? Challenging the dominant discourse of reading. Gender and Education, 30(8), 1048-1064.

Bourdieu, Pierre (1984). Distinction. Harvard University Press.

Bourdieu, Pierre (1992). The logic of practice. Polity Press.

Bourdieu, Pierre (2002). Habitus. I Jean Hillier, \& Emma Rooksby (red.), Habitus: A sense of place (s. 27-34). Ashgate.

Brozo, William G. (2019). Engaging Boys in Active Literacy: Evidence and Practice. Cambridge University Press.

Cann, Victoria (2018). Girls like this, boys like that: The reproduction of gender in contemporary youth cultures. Bloomsbury Publishing. 
Cho, Sumi, Crenshaw, Kimberlé Williams, \& McCall, Leslie (2013). “Toward a Field of Intersectionality Studies: Theory, Applications, and Praxis.” Signs: Journal of Women in Culture and Society, 38(4), 785-810.

Comber, Barbara (2015). Critical literacy and social justice. Journal of Adolescent \& Adult Literacy, 58(5), 362-367.

Connell, Raewyn (1995). Masculinities. University of California Press.

Crenshaw, Kimberlé Williams (1991). Mapping the margins: Intersectionality, identity politics, and violence against women of color. Stanford Law Review, 43(6), 1241-1299.

Cremin, Teresa, Mottram, Marylin, Collins, Fiona, Powell, Sacha, \& Drury, Rose (2012). Building Communities: Teachers Researching Literacy Lives. Improving Schools, 15(2), 101-115.

De Fina, Anna (2013). Positioning level 3: Connecting local identity displays to macro social processes. Narrative Inquiry, 23(1), 40-61.

Dutro, Elisabeth (2003). 'Us boys like to read football and boy stuff: Reading masculinities, performing boyhood. Journal of Literacy Research, 34(4), 465-500.

Entwisle, Doris R., Alexander, Karl L., \& Olson, Linda S. (2007). Early schooling: The handicap of being poor and male. Sociology of Education, 80(2), 114-138.

Freire, Paulo (1993). Pedagogy of the Oppressed. Penguin.

Freeman, Mark (2010). Hindsight. The Promise and Peril of Looking Backward. Oxford University Press.

Goodson, Ivor (1996). An alternative culture for teaching. Curriculum and Teaching, 11(1), 87-92.

Goodson, Ivor (2013). Developing narrative theory: Life histories and personal representation. Routledge.

Guthrie, John, \& McRae, Aangela 2011. Reading Engagement among African American and European American Students. I Jay S. Samuels, \& Alan E. Farstrup (red.), What Research Has to Say about Reading Instruction (4 uppl. s.115-142). International Reading Association.

Hammet, Roberta F., \& Sanford, Kathy (red.). (2008). Boys, girls \& the myths of literacies \& learning. Canadian Scholars' Press Inc.

Hultin, Eva (2006). Samtalsgenrer i gymnasieskolans litteraturundervisning. En ämnesdidaktisk studie (Örebro Studies in Education, nr. 16). [Doktorsavhandling, Örebro universitet].

Högberg, Ronny (2011). Cheating as subversive and strategic resistance: Vocational students' resistance and conformity towards academic subjects in a Swedish upper secondary school. Ethnography and Education, 6(3), 341-355. 
Jackson, Carolyn (2010). 'I've been sort of laddish with them ... one of the gang': Teachers' perceptions of 'Laddish' boys and how to deal with them. Gender and Education, 22(5), 501-509.

Janks, Hillary (2010). Literacy and power. Routledge.

Janks, Hillary, \& Vasquez, Vivian (2011). Critical literacy revisited: Writing as critique. English Teaching, 10(1), 1.

Karlsson, Marie (2020). A question of time and place: student tutors' narrative identities in for-and non-profit contexts in Sweden. Compare: A Journal of Comparative and International Education, 1-16.

Kirkland, David E. (2011). Books like clothes: Engaging young Black men with reading. Journal of Adolescent \& Adult Literacy, 55(3), 199-208.

Kohler Reissman, Catherine (2008): Narrative Methods for the Human Sciences. Sage Publications.

Kontio, Janne (2016). Auto mechanics in English: Language use and classroom identity work [Doktorsavhandling, Acta Universitatis Upsaliensis, Uppsala universitet].

Ljung Egeland, Birgitta (2019). Narratives of Belonging: Migrant Children's Friendship Negotiation. I Valerie Margrain, \& Annica Löfdahl Hultman (red.), Challenging Democracy in Early Childhood Education (s. 183-196). Springer.

Love, Kristina, \& Hamston, Julie (2004). Committed and reluctant male teenage readers: Beyond bedtime stories, Journal of Literacy Research, 36(3), 335-400.

Luke, Allan (2012). Critical literacy: Foundational notes. Theory into practice, 51(1), 411.

Löfgren, Håkan, \& Karlsson, Marie (2016). Emotional aspects of teacher collegiality: A narrative approach. Teaching and Teacher Education, 60, 270-280.

Mac an Ghaill, Mairtin (1994). The making of men: Masculinities, sexualities, and schooling. Open University Press.

Massey, Doreen (2005). For Space. Sage.

Mishler, Elliot G. (1999). Storylines: Craftartists' narratives of identity. Harvard University Press.

Molloy, Gunilla (2002). Läraren- litteraturen-eleven. En studie om läsning skönlitteratur på bögstadiet. [Doktorsavhandling, Stockholm: Lärarhögskolan].

Molloy, Gunilla (2007). När pojkar läser och skriver. Studentlitteratur.

Moss, Gemma (2007). Literacy and gender: Researching texts, contexts and readers. Routledge.

Moss, Gemma (2011). Policy and the search for explanations for the gender gap in literacy attainment. Literacy, 45(3), 111-118. 
Muntoni, Francesca, \& Retelsdorf, Jan (2018). Gender-specific teacher expectations in reading - The role of teachers' gender stereotypes. Contemporary Educational Psychology, 54, 212-220.

Nash, Jennifer C. (2008). Re-thinking intersectionality. Feminist review, 89(1), 1-15.

Pérez Prieto, Héctor (2000). Historien om räven och andra berättelser. Om klasskamrater och skolan på en liten ort - ur ett skol- och livsberättelseperspektiv. Pedagogisk Forskning i Uppsala 137.

Pérez Prieto, Héctor (2006). Berättaren och berättelsen i centrum. I Karin Anna Petersen, Stinne Glasdam, \& Vibeke Lorentzen (red), Livshistorieforskning og Kvalitative Interview (s. 288-307). PUC.

Persson, Magnus (2012). Den goda boken. Samtida föreställningar om litteratur och läsning. Studentlitteratur.

Persson, Magnus (2015). Reading around the text: On the diversity of reading practices in the new popular literary culture. L1-Educational Studies in Language and Literature, 15, 1-18.

Reay, Diane (2017). Miseducation. Inequality, education and the working classes. Polity Press.

Roberts, Steven (2018). Young working-class Men in transition. Routledge.

Sanford, Kathy, \& Blair, Heather (2008). Game boys: Where is the literacy?. I Roberta B. Hammett, \& Kathy Sanford (red.), Boys, girls \& the myths of literacies \& learning (s.199-215). Canadian Scholars' Press.

Scholes, Laura (2019). Working-class boys' relationships with reading: contextual systems that support working-class boys' engagement with, and enjoyment of, reading. Gender and Education, 31(3), 344-361.

Scholes, Laura (2020). Scholes, L. (2020). Recognition of boys as readers through a social justice lens. British Journal of Sociology of Education, 41(7), 975-991.

Scholes, Laura, \& Asplund, Stig-Börje (2021). The making of male reader identities across generations: assemblages of rural places in shaping life as a male reader in Australia and Sweden. British Journal of Sociology of Education, 42(8), 1192-1209.

Scholes, Laura, Spina, Nerida, \& Comber, Barbara (2020) Disrupting the 'boys don't read' discourse: Primary school boys who love reading fiction. British Educational Research Journal, 47(1), 163-189.

Schmidt, Catarina (2018). Barns läspraktiker i ett demokratiskt samhälle. Utbildning \& Demokrati, 27(3), 77-99.

Skeggs, Beverley. (2004). Class, self and culture. Routledge.

Smith, Michael W., \& Jeffrey D. Wilhelm. (2002). Reading Dont Fix No Chevys'. Literacy in the Lives of Young Men. Heinemann.

SOU (2018:57). Barns och ungas läsning - ett ansvar för hela sambället. Betänkande av läsdelegationen. Regeringskansliet. 
https://www.regeringen.se/49f088/contentassets/39759a0cb5234aa08340c7243e 371908/barns-och-ungas-lasning--ett-ansvar-for-hela-samhallet-sou-201857.pdf

Street, Brian V., \& Brian B. Street. (1984). Literacy in theory and practice. Vol. 9. Cambridge University Press.

Sundström Sjödin, Elin (2019). Where is the critical in literacy?: Tracing performances of literature reading, readers and non-readers in educational practice. [Doktorsavhandling, Örebro Universitet].

Sundström Sjödin, Elin (2020). Empowerment (s) in practice: reading literature in a critical space. Pedagogy, Culture \& Society, ahead of print, 1-18.

Tattersall Wallin, Elisa, \& Nolin, Jan (2020). Time to read: Exploring the timespaces of subscription-based audiobooks. New media \& society, 22(3), 470-488.

Thatcher, Jenny, Ingram, Nicola, Burke, Ciaran, \& Abrahams, Jessie (2016). Bourdieu: The next generation. The development of Bourdieu's intellectual heritage in contemporary UK sociology. Routledge.

Young, Josephine Payton (2000). Boy talk: Critical literacy and masculinities. Reading Research Quarterly, 35(3), 312-337.

Young, Josephine Payton \& Brozo, William G. (2001). Boys will be boys, or will they? Literacy and masculinities. Reading Research Quarterly, 36(3), 316-325.

Vetenskapsrådet (2017). God forskningssed [Elektronisk resurs]. Vetenskapsrådet. https://www.vr.se/download/18.2412c5311624176023d25b05/1555332112063/ God-forskningssed_VR_2017.pdf

Walsh, Maureen (2008). Worlds have collided and modes have merged: Classroom evidence of changed literacy practices. Literacy, 42(2), 101-108.

Ward, Michael, Tarrant, Aanna, Terry, Gareth, Featherstone, Brid, Robb, Martin, \& Ruxton, Sandy (2017). Doing gender locally: The importance of 'place' in understanding young men's masculinities in the male role model debate. Sociological Review, 65(4), 797-815.

Watson, Anne (2011). Not Just a 'Boy Problem': An Exploration of the Complexities Surrounding Literacy under-Achievement. Discourse: Studies in the Cultural Politics of Education, 32(5), 779-795.

Webb, Andrew (2019). Getting there and staying in: first-generation indigenous students' educational pathways into Chilean higher education. International Journal of Qualitative Studies in Education, 32(5), 529-546.

Wilhelm, Jeffrey, \& Smith, Michael W. (2014). Reading unbound: Why kids need to read what they want- and why we should let them. Scholastic.

Willis, Paul (1977). Learning to labour: How working class kids get working class jobs. Columbia University Press.

Åberg, Magnus, \& Hedlin, Maria (2015). Happy objects, happy men? Affect and materiality in vocational training. Gender and Education, 27(5), 523-538. 